\title{
La tradition épique, du Moyen Âge au XIX siècle. Partie thématique sous la direction de François Suard
}

\author{
Maria Colombo Timelli
}

\section{(2) OpenEdition}

\section{Journals}

Édition électronique

URL : https://journals.openedition.org/studifrancesi/25932

DOI : $10.4000 /$ studifrancesi.25932

ISSN : 2427-5856

Éditeur

Rosenberg \& Sellier

Édition imprimée

Date de publication : 1 avril 2007

Pagination : 145-146

ISSN : 0039-2944

\section{Référence électronique}

Maria Colombo Timelli, «La tradition épique, du Moyen Âge au xix siècle. Partie thématique sous la direction de François Suard », Studi Francesi [En ligne], 151 (LI | I) | 2007, mis en ligne le 30 novembre 2015, consulté le 23 novembre 2021. URL : http://journals.openedition.org/studifrancesi/25932 ; DOI : https://doi.org/10.4000/studifrancesi.25932

Ce document a été généré automatiquement le 23 novembre 2021.

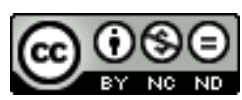

Studi Francesi è distribuita con Licenza Creative Commons Attribuzione - Non commerciale - Non opere derivate 4.0 Internazionale. 


\title{
La tradition épique, du Moyen Âge au $X I X{ }^{\mathrm{e}}$ siècle. Partie thématique sous la direction de François Suard
}

\author{
Maria Colombo Timelli
}

\section{RÉFÉRENCE}

La tradition épique, du Moyen Âge au XIXe siècle. Partie thématique sous la direction de François SUARD, à la mémoire d'Alain Labbé, «Cahiers de Recherches Médiévales», n. 12, 2005.

Un premier groupe d'articles correspond à la partie monographique de cette issue.

2 Claude Roussel (L'automne de la chanson de geste, pp. 15-28) brosse un tableau d'ensemble des chansons de geste en vers du XIV siècle: selon le classement proposé par François Suard et adopté ici, on peut distinguer remaniements, compilations, suites, œuvres originales. Ces textes, qui répondent bien à l'intention affichée de conter 'd'armes et d'amours', combinent des thèmes d'origine diverse: motifs populaires, folkloriques, et même courtois; si l'amour demeure marginal et conventionnel, c'est plutôt l'inspiration guerrière et apologétique qui s'affirme, avec des éléments qui remontent à la tradition hagiographique. La vitalité de la chanson de geste au XIV siècle est certaine: elle profite indubitablement d'un héritage prestigieux qu'elle associe à une inspiration renouvelée par des matériaux hétérogènes. Il s'agit cependant d'un succès fragile: de fait, comme le souligne C.R., la chanson de geste 'tardive' se distingue de moins en moins du roman.

François SUARD (Le passage à la prose, pp. 29-43) examine quelques traits caractéristiques des textes en prose après 1450, et d'abord le propos didactique assumé par les auteurs, associé à la proclamation du plaisir de la lecture, désormais facilitée par la forme plus usuelle de la prose. La comparaison entre des réécritures 'doubles' (les Loherains selon le ms. Ars. 3346 et le remaniement de David Aubert, le Galien des mss. BnF fr. 1470 et Ars. 3351), ou encore entre plusieurs proses, sur le plan de l'organisation textuelle et 
des traits stylistiques, permet à F.S. d'aller au-delà des résultats venant de la comparaison ponctuelle entre chaque mise en prose et son propre modèle, en relevant des traits communs propres des réécritures 'épiques' du $\mathrm{Xv}^{\mathrm{e}}$ siècle.

Sarah BAUDelle-Michels, La fortune de 'Renaut de Montauban', pp. 103-114. La longévité exceptionnelle de Renaut de Montauban (qui compte des refontes en vers dès le XIII ${ }^{\mathrm{e}}$ siècle, des remaniements au XIV e, puis le passage à la Bibliothèque Bleue et encore des réécritures à partir $\mathrm{du} \mathrm{XVIII}^{\mathrm{e}}$ siècle jusqu'à la récente réorientation dans la littérature pour l'enfance) peut être expliquée par l'esthétique de la réception de Jauss, permettant de prendre en compte la plasticité du texte et sa capacité de se prêter à des lectures renouvelées: de fait, les réécritures successives ne font que rendre explicites des données déjà présentes dans le modèle.

5 Catherine GAULLIER-BOUgASSAS, Le Chevalier au Cygne à la fin du Moyen Âge: renouvellements, en vers et en prose, de l'épopée romanesque des origines de Godefroy de Bouillon, pp. 115-146). Après avoir souligné le grand succès de la légende tout au long du Moyen Âge français, C.G.-B. compare la Chanson du Chevalier au Cygne et de Godefroy de Bouillon en laisses épiques (XIV siècle) et la version en prose que Berthault de Villebresme réalisa vers 1470 pour Marie de Clèves. Malgré la conservation d'une forme plus traditionnelle, l'auteur de la Chanson renouvelle profondément la matière et modifie ses sources d'inspiration, alors que le prosateur, qui adopte l'attitude du moraliste, rédige, sous une forme littéraire apparemment plus 'moderne', un récit exemplaire dépourvu d'originalité.

6 Jean-Charles HERBIN propose une réflexion de synthèse sur l'organisation du 'cycle' dit des Loherains (Variations, vie et mort des 'Loherains'. Réflexions sur la gestation et les paradoxes d'un grand cycle épique, pp. 147-174). Selon son hypothèse, le noyau plus ancien est constitué de la Mort Begon, sans doute fondée sur un événement historique; durant le $\mathrm{XII}^{\mathrm{e}}$ siècle se serait mis en forme un 'Cycle primitif', comprenant Garin et Gerbert; pendant les premières décennies du XIII', le 'Grand cycle' aurait été complété par Hervis et Yonnet de Metz, donnant une conclusion lorraine à l'ensemble; la place de la Vengeance Fromondin et d'Anseÿs de Gascogne demeure cependant problématique. Malgré son énorme succès, dont témoignent trois mises en prose aux $\mathrm{Xv}^{\mathrm{e}}$ et $\mathrm{XVI}^{\mathrm{e}}$ siècles, la geste ne fut pas imprimée. Récupérée et éditée partiellement, puis critiquement, à partir du XIX elle jouit aujourd'hui d'une certaine fortune critique, comme le prouve la bibliographie réunie par J.-C.H. aux pp. 167-174 (150 entrées pour les années 1991-2005).

7 Le succès de la matière épique se prolonge sans interruption jusqu'à nos jours: Bernard GUIDOT (La 'manière' d'Alfred Delvau: un nouveau regard sur le Moyen Âge, pp. 83-101) examine les modalités de réécriture mises en œuvre par Alfred Delvau dans ses Collections de romans de chevalerie (1869), à partir de trois exemples: Huon de Bordeaux, Fier-A-Bras, Guérin de Monglave. En poursuivant le chemin ouvert au siècle précédent par le marquis de Paulmy et par le comte de Tressan parmi d'autres, Delvau, attiré par le passé et moderne de par sa formation, voulant plaire au plus grand nombre, utilise le Moyen Âge comme un prétexte: il ne se prive pas d'exprimer ses idées personnelles avec fermeté, accentue le pathétique, et montre un sens réel de la dramatisation; sensible aux aspects linguistiques et stylistiques, il mélange mots de couleur médiévale et langue contemporaine, style de tonalité 'populaire' et allusions érudites. Il serait néanmoins intéressant de savoir - ce que B.G. ne spécifie pas - à partir de quels modèles A. Delvau a réalisé ses propres récits. 
Deux contributions constituent la section Varia. La première, de Myriam wHITE (Péché et conscience de soi dans 'L'Espurgatoire seint Patriz' de Marie de France, pp. 177-189) reconnaît dans un sens profond de culpabilité la motivation qui explique et justifie le voyage du chevalier Owein dans l'au-delà. Ce voyage serait en même temps un moyen de se découvrir soi-même et d'affirmer la cohésion entre les morts et les vivants grâce à la fonction reconnue à la prière d'intercession. Dans la deuxième (L'illustration de 'La Fleur des histoires d'Orient' dans le ms. New York, Pierpont Morgan Library, M.723, pp. 191-204), Jean-François KostA-THÉFAINE étudie le rapport texte-image dans le manuscrit newyorkais qui transmet, outre la version française du texte de Hayton, le Devisement $d u$ Monde de Marco Polo: bien que les dates soient objet de discussion, la confection de ce manuscrit semble se situer entre l'extrême fin $\mathrm{du}_{\mathrm{XIV}}{ }^{\mathrm{e}}$ et le tout début du $\mathrm{xv}^{\mathrm{e}}$ siècle. Dans les sept images concernées, qui représentent des scènes de culte religieux, des scènes de bataille et des empereurs, J.-F.K.-T. relève un exotisme de convention et montre comment l'illustrateur a dû s'inspirer, non pas des rubriques, largement insuffisantes, mais du texte lui-même.

9 La section Regard sur une cuvre concerne le Roman de Silence, objet entre autres d'une édition italienne récente par Anna Airò (Roma, Carocci, 2005: cf. SF, 149, 2005, p. 368); on signalera d'abord la mise à jour bibliographique de Silvère Menegaldo et Danièle James-Raoul (pp. 207-210), dont une nouvelle édition du roman est annoncée dans les «CFMA». Un premier article, de Silvère MENEGALDo (Merlin et la scolastique: de la 'coincidentia oppositorum' à la 'quaestio disputata' dans 'Le Roman de Silence', pp. 211-225), souligne essentiellement le caractère contradictoire du roman, assumant même la contradiction comme sens ultime et moteur du récit (cf. le débat entre Nature et Noreture, ou la question centrale du sexe de la protagoniste). Selon S.M. un tel débat qui se pose à tous les niveaux et auprès de toutes les voix du conte, narrateur et actants compris - pourrait être le reflet de la 'quaestio disputata' telle qu'elle se pratiquait dans l'Université du xiII ${ }^{\mathrm{e}}$ siècle; d'autre part, la lecture pragmatique du récit serait le niveau d'interprétation qui révèle le mieux les intentions d'Heldris de Cornouaille. Dans une dernière contribution, Danièle JAMES-RAOUL (La poétique de la lettrine dans 'Le Roman de Silence', pp. 227-245) cherche dans les 128 lettrines du manuscrit unique du roman des indications sur la structuration de l'histoire. Relativement bien réparties dans l'ensemble du texte, elles semblent obéir à des instances narratives (isolement d'unités, de scènes, de passages dialogués) et souligner les structures temporelle, actancielle et discursive. Malgré l'intérêt de certaines remarques (par exemple, sur le plan métrique, D.J.-R. relève qu'aucune lettrine ne brise le couplet), des cas 'résiduels' résistent à toute tentative d'interprétation, et l'on est obligé de conclure sur le manque d'un véritable esprit de système chez le copiste. 